\title{
Caries Experience and Its Relationship with Parent's Education, Occupation and Socio Economic Status of the family among 3-6 Years Old Preschool Children of Sri Ganganagar City, India
}

\author{
Dr. Ridhi Narang ${ }^{1, *}$, Dr. Litik Mittal ${ }^{2}$, Dr. Kunal Jha ${ }^{3}$, Dr. Anamika ${ }^{1}$, Dr. Roseka ${ }^{4}$ \\ ${ }^{1}$ Department of Public Health Dentistry, Surendera Dental College and Research Institute, Sri Ganganagar-335001, Rajasthan, India \\ ${ }^{2}$ Department of Conservative Dentistry and Endodontics, Surendera Dental College and Research Institute,Sri Ganganagar-335001, \\ Rajasthan, India \\ ${ }^{3}$ Department of Public Health Dentistry, Kalinga Institute of Dental sciences, KIIT University, Bhubeneswar, Odisha \\ ${ }^{4}$ Dept of Conservative Dentistry and Endodontics, Uttranchal Dental and Medical Research Institute, Dehradun- Uttarakhand \\ *Corresponding Author:ridhinarang@gmail.com
}

Copyright@ 2013Horizon Research Publishing All rights reserved.

\begin{abstract}
Aim: The aim of the present study was to assess the caries experience and its relationship with parent's education, occupation and socio economic status of the family among 3-6 years old preschool children of Sri Ganganagar city, India. Material and methods: A sample of 512 preschool going children were selected. The socioeconomic status was elicited using modified B.G.L. Prasad's classification for the year 2010. Parent's education, occupation and income were recorded. Dental caries experience was recorded using Dentition status and treatment needs (WHO Basic Oral Health Survey 1997). Association between Socioeconomic status and caries experience was obtained using chi square test. Results: The prevalence of nursing caries was $33.01 \%$.Nursing caries was significantly associated with lower parents education, occupation and socioeconomic status of the family $(\mathrm{p}<0.001)$. Conclusion: Instilling the positive attitudes of the parents especially mothers towards the prevention of nursing caries would reduce the prevalence at this tender age of life.
\end{abstract}

Keywords Nursing Caries, Preschool, Early Childhood Caries, Education, Occupation

\section{Introduction}

Dental caries afflicts humans of all. It is a disease caused due to complex interplay of social, behavioral, cultural, dietary and biological risk factors[1,2]. Demographic factors such as age, oral hygiene, socio economic and cultural characteristics can affect the development of nursing caries. Low parental education, family income and single marital status also pre dispose to nursing caries[3].

In Asia, in the Far East region, which seems to have one of the highest prevalence and severity for the disease, the prevalence in three year olds ranges from $36 \%$ to $85 \%$ [1] while in India a prevalence of $44 \%$ has been reported for caries in 8 to 48 months old. 4 The caries prevalence in the preschool children of Hubli and Dharwad city was $54.1 \%$ [3]. One such study done in Kanpur district of Uttar Pradesh has reported nursing caries prevalence of $58 \%[5]$.

Data regarding prevalence of nursing caries is not available in this part of the country. Hence the present study was undertaken and also as caries can be effectively prevented early identification of dental caries in children provides an opportunity to identify youngsters at high[6].

\section{Material and Method}

The present cross-sectional study was carried out to assess the prevalence of nursing caries and its relationship with parent's education, occupation and socio economic status of the family in 3-6 years old preschool children of Sri Ganganagar city. India.

A pilot study was conducted using the proforma on 30 preschool children to assess the operational feasibility of the study.

Sample size was calculated using the standard formula seeking results at $95 \%$ Confidence Interval for which the value of $\mathrm{z}=1.96$, the allowable error (e) taken as 0.05 . Thus using the above mentioned formula, pilot study conducted and the prevalence of the disease, sample of 512 preschool going children was obtained.

A written consent was obtained from the school authorities before the commencement of this study. Informed consent was obtained from mothers / guardians for the examination of their children. Approval to carry out the study was obtained from the Ethical Committee of the Institution. 


\begin{tabular}{|c|c|c|}
\hline 0 & NBS negative & $\begin{array}{c}\text { Dentition is caries free or caries pattern does not conform to descriptions associated } \\
\text { with scores } 1,2 \text { or } 3\end{array}$ \\
\hline 1 & Mild & $\begin{array}{r}\text { Caries on: } \\
\text { a) labial and/or palatal surface of one or more of the maxillary incisors. } \\
\text { b) buccal,palatal or occlusal surfaces of one or both of the maxillary 1st molars. }\end{array}$ \\
\hline 2 & Moderate & $\begin{array}{r}\text { Caries on: } \\
\text { a) labial and/or palatal surface of one or more of the maxillary incisors. } \\
\text { buccal,palatal or occlusal surfaces of one or both of the maxillary 1st molars. } \\
\text { c) buccal or occlusal surface of one or both of the mandibular 1st molars. }\end{array}$ \\
\hline 3 & Severe & $\begin{array}{c}\text { Same clinical picture as score 2 except that one or more of the designated teeth has } 3 \\
\text { or more surfaces with contiguous decay. }\end{array}$ \\
\hline
\end{tabular}

The proforma had two parts: the first part consisted of a predesigned and pretested questionnaire. Information regarding demographic data like name, age, gender, Parent's education, occupation and income were elicited. The socioeconomic status was elicited using modified B.G.L. Prasad's classification for the year 2010 (SOCIAL CLASS = value of CPI of the year x 4.93 / 100) [7].

The second part consisted of clinical assessment. The diagnostic criteria for nursing caries were according to Babeely K et al 1989[8]. The prevalence of nursing caries was recorded using "Dentition status and treatment needs" (WHO basic oral health assessment form 1997) [9].

It was established during the study that on an average, it took about 15-20 minutes to examine a child.15-20 were interviewed and examined in any given day during the survey period excluding the weekends.

Plain mouth mirrors and CPI Probe were used in the survey. Disposable mouth masks and gloves were worn by examiner during examination. Autoclaved clinical examination instruments of 25 sets were carried for inspection. In some needed situations chemical method of disinfection was followed using cold solution Korsolex (Glutaraldehyde - 7.0 gms; 1-6 dihydroxy 2.5 dioxyhexane - 8.2 gms and polymethyl urea derivative - 11.6 gms) diluted by adding 1 part to 9 parts of potable water for 15 minutes.

Chi-square test was used to test the significance of the association between parent's education, occupation and socioeconomic status with nursing caries experience.

\section{Results}

Out of the 512 subjects examined, $65.2 \%$ (334) were males and $34.8 \%$ (178) were females. On the whole $33.1 \%$ (169) had nursing caries while $66.9 \%$ (343) children had no caries. Out of 169 children with nursing caries, majority of them were males $(61.5 \%: 104)$ with $38.5 \%$ (65) females. No statistically significant difference in prevalence of nursing caries was found between males and females $(\mathrm{p}=0.22)$.

Table 1 shows the distribution of caries experience of children according to their father's education. Children whose father had lesser education had a statistically highly significant caries experience $(p<0.001)$ than children whose father had higher education.
Table 1. Distribution of nursing caries experience of the children in relation to their father's education

\begin{tabular}{|c|c|c|c|c|}
\hline Father's education & \multicolumn{2}{|c|}{$\mathrm{dmft} 0$} & \multicolumn{2}{c|}{$\mathrm{dmft} \geq 1$} \\
\hline & $\mathrm{n}$ & $\%$ & $\mathrm{n}$ & $\%$ \\
\hline Primary school & 04 & $11.2 \%$ & 32 & $88.8 \%$ \\
\hline High school & 85 & $56.0 \%$ & 67 & $44.0 \%$ \\
\hline University & 253 & $79.1 \%$ & 67 & $20.9 \%$ \\
\hline Illiterate & 01 & $25.0 \%$ & 03 & $75.0 \%$ \\
\hline Total & 343 & $66.9 \%$ & 169 & $33.1 \%$ \\
\hline & $\chi^{2}=83.53, \mathrm{p}<0.001$ \\
\hline
\end{tabular}

Table 2 shows the distribution of caries experience of children according to their mother's education. Children whose mother had lesser education had a statistically highly significant caries experience $(p<0.001)$ than children whose mother had higher education.

Table 2. Distribution of nursing caries experience of the children in relation to their mother's education

\begin{tabular}{|c|c|c|c|c|}
\hline Mother's education & \multicolumn{2}{|c|}{ dmft 0 } & \multicolumn{2}{c|}{$\mathrm{dmft} \geq 1$} \\
\hline & $\mathrm{n}$ & $\%$ & $\mathrm{n}$ & $\%$ \\
\hline Primary school & 21 & $30.8 \%$ & 47 & $69.2 \%$ \\
\hline High school & 99 & $56.9 \%$ & 75 & $43.1 \%$ \\
\hline University & 216 & $83.8 \%$ & 42 & $16.2 \%$ \\
\hline Illiterate & 07 & $58.3 \%$ & 05 & $41.7 \%$ \\
\hline Total & 343 & $66.9 \%$ & 169 & $33.1 \%$ \\
\hline & $\chi^{2}=81.18, \mathrm{p}<0.001$ & \\
\hline
\end{tabular}

Table 3 shows distribution of nursing caries experience of the children in relation to their father's occupation. Children whose fathers had lower level of occupation had statistically highly significant caries experience $(p<0.001)$ than children whose father had higher level of occupation. 
Table 3. Distribution of nursing caries experience of the children in relation to their father's occupation

\begin{tabular}{|c|c|c|c|c|}
\hline \multirow{2}{*}{ Father's occupation } & \multicolumn{2}{|c|}{$\mathrm{dmft} 0$} & \multicolumn{2}{c|}{$\mathrm{dmft} \geq 1$} \\
\cline { 2 - 5 } & $\mathrm{n}$ & $\%$ & $\mathrm{n}$ & $\%$ \\
\hline Professional & 224 & $84.5 \%$ & 40 & $15.5 \%$ \\
\hline Semi professional & 38 & $50.7 \%$ & 37 & $49.3 \%$ \\
\hline Clerical /shop keeper/farmer & 53 & $49.1 \%$ & 55 & $50.9 \%$ \\
\hline Skilled & 10 & $50.0 \%$ & 10 & $50.0 \%$ \\
\hline Semi skilled & 08 & $29.6 \%$ & 21 & $70.3 \%$ \\
\hline Unskilled & 10 & $55.6 \%$ & 08 & $44.4 \%$ \\
\hline Unemployed & 0 & $0 \%$ & 0 & $0 \%$ \\
\hline Total & 343 & $66.9 \%$ & 169 & $33.1 \%$ \\
\hline \multicolumn{2}{|c|}{$\chi^{2}=86.46, \mathrm{p}<0.001$} & & \\
\hline
\end{tabular}

Table 4 shows distribution of nursing caries experience of the children in relation to their mother's occupation. Children whose mothers were unemployed had a statistically highly significant $(\mathrm{p}<0.001)$ caries experience compared to children whose mothers were professionals.

Table 4. Distribution of nursing caries experience of the children in relation to their mother's occupation

\begin{tabular}{|c|c|c|c|c|}
\hline \multirow{2}{*}{ Mother's occupation } & \multicolumn{2}{|c|}{$\mathrm{dmft} 0$} & \multicolumn{2}{c|}{$\mathrm{dmft} \geq 1$} \\
\cline { 2 - 5 } & $\mathrm{N}$ & $\%$ & $\mathrm{~N}$ & $\%$ \\
\hline Professional & 120 & $89.6 \%$ & 14 & $10.2 \%$ \\
\hline Semi professional & 17 & $66.3 \%$ & 09 & $34.7 \%$ \\
\hline Clerical /shop keeper/farmer & 02 & $66.7 \%$ & 01 & $33.3 \%$ \\
\hline Skilled & 01 & $100 \%$ & 0 & $0 \%$ \\
\hline Semi skilled & 0 & $0 \%$ & 0 & $0 \%$ \\
\hline Unskilled & 02 & $100 \%$ & 0 & $0 \%$ \\
\hline Unemployed & 201 & $58.1 \%$ & 145 & $41.9 \%$ \\
\hline Total & 343 & $66.9 \%$ & 169 & $33.1 \%$ \\
\hline \multicolumn{2}{|c|}{$\chi^{2}=43.66, \mathrm{p}<0.001$} & & \\
\hline
\end{tabular}

Table 5. Distribution of nursing caries experience of the children in relation to socio-economic status of the family

\begin{tabular}{|c|c|c|c|c|}
\hline \multirow{2}{*}{ Socio- economic status of family } & \multicolumn{2}{|c|}{$\mathrm{dmft} 0$} & \multicolumn{2}{c|}{$\mathrm{dmft} \geq 1$} \\
\cline { 2 - 5 } & $\mathrm{n}$ & $\%$ & $\mathrm{n}$ & $\%$ \\
\hline Upper class(278) & 216 & $77.7 \%$ & 62 & $22.3 \%$ \\
\hline Upper middle(104) & 65 & $62.5 \%$ & 39 & $37.5 \%$ \\
\hline Lower middle(82) & 48 & $58.3 \%$ & 34 & $41.7 \%$ \\
\hline Upper lower(48) & 14 & $29.1 \%$ & 34 & $70.9 \%$ \\
\hline Lower class(0) & 0 & $0 \%$ & 0 & $0 \%$ \\
\hline Total & 343 & $66.9 \%$ & 169 & $33.1 \%$ \\
\hline \multicolumn{2}{|c|}{$\chi^{2}=49.07, \mathrm{p}<0.001$} & & \\
\hline
\end{tabular}

Table 5 shows the distribution of nursing caries experience in relation to socioeconomic status of the family. Children belonging to lower socioeconomic status had a statistically highly significant $(\mathrm{p}<0.001)$ caries experience compared to children belonging to other socioeconomic classes.

\section{Discussion}

The children of the present study belonged to 3-6 years group. Similar age groups of 3-6 years children were studied by Yang Li et al[10]. However in the study of Mahejabeen R et al[3] 3-5 years age group children were included.

The prevalence of nursing caries in the present study was $33.1 \%$. A lower prevalence of nursing caries was reported by Raadal et al[11] (5.5\%) in Sudan and Mousami Goswami Singh et al[12] (30.6\%) in Moradabad City of Uttar Pradesh. A higher prevalence of nursing caries was reported by S. Sunitha et al[6] (36\%) in Davangere city.

The prevalence of nursing caries had varied in each of the reported studies. This could be related to lack of universally accepted definition of nursing caries and no suitable epidemiologic index for measurement of nursing caries[13].

In the present study even though the females had a higher nursing caries prevalence than the males, the difference was not significant $(\mathrm{p}=0.22)$. Similar findings were reported in studies conducted by Yang Li et al[10], Wyne et al [14], R. Tyagi [2] and Babu Jose et al [4]. The probable reason could be the early eruption and longer retention of the teeth in females than males.

In the present study lower prevalence and lower mean dmft scores have been significantly $(p<0.001, p=0.00)$ related to higher levels of education and occupation either of both parents or of the mother or father alone. Similar findings were reported by S.C.L. Chan et al[15] and Simin Z. Mohebbi et al[16]. However, a study by Chaiana Piovesan et al[17] reported no significant association between nursing caries and education and occupation level of father or mother. The reason for lower mean dmft among children could be that parents have more knowledge and are aware of the importance of oral health which further influences behavior related to dental health of child as to maintain good dietary habits and hygiene.

In the present study the prevalence of nursing caries was higher in Class IV social group with similar findings by Grytten et al[18], Chosack et al[19], Grindefjord et al[20], Tyagi R[2] and Babu Jose et al[4]. The reason may be that the individuals from lower socioeconomic status experience financial, social and material disadvantages that compromise their ability to care for themselves afford professional health care services and live in healthy environment. In addition, Low socio economic status individuals have more fatalistic beliefs about their health and have a lower perceived need for care, leading to less self care and lower utilization of preventive health services. The possible influences of socio-economic status on dental health may also be a 
consequence of differences in dietary habits and the role of sugar in the diet.

\section{Conclusion}

Nursing caries was significantly associated with lower parent's education, occupation and socioeconomic status of the family. Instilling the positive attitudes of the parents towards the prevention of nursing caries would reduce the prevalence at this tender age of life.

\section{REFERENCES}

[1] Simratvir M, Mogha GA, Thomas AM, Singh N, Chopra S. Evaluation of caries experience in 3-6 year old children, and dental attitudes amongst the caregivers in the Ludhiana city. Journal of Indian Society of Pedodontics and Preventive Dentistry 2009; 27(3):164-69.

[2] R. Tyagi. The prevalence of nursing caries in Davangere preschool children and its relationship with feeding practices and socio economic status of the family. Journal of Indian Society of Pedodontics and Preventive Dentistry 2008 December: 153-57.

[3] Mahajebeen R, Sudha P, Kulkarni SS, Anegundi R. Dental caries prevalence among preschool children of Hubli: Dharwad city. Journal of Indian Society of Pedodontics and Preventive Dentistry 2006; 24:19-22.

[4] Jose B, King NM. Early childhood caries lesion in preschool children in Kerala, India. Pediatric Dentistry 2003; 25:594-600.

[5] C.L. Dileep, Basavaraj. P, Jayaprakash. K and Rajat Bhargava. Dental caries experience among Kindergarten school going children of Lakhanpur, Kanpur, India. Journal of the Indian Association of Public Health Dentistry 2007; 9; 60-62.

[6] S. Sunitha, G.N. Chandu, K. Pushpanjali, S.H. Jayashree and Md.Shafiulla. Feeding habits and early childhood caries (ECC) among preschool children of Davangere City, Karnataka. Journal of the Indian Association of Public Health Dentistry $2006 ; 7: 39-42$

[7] Prasad BG. Social Classification of Indian families. J Indian Med Assoc 1961; 37: 250-51.

[8] Babeely K, Kaste LM, Husain J, Behbehani J, Al-Za'abi F, Mahar TC, Tavares M, Soparkar P, DePaola P. Severity of nursing bottle syndrome and feeding patterns in Kuwait. Community Dentistry and Oral Epidemiology 1989;
$17: 237-39$

[9] WHO Oral Health Surveys; Basic methods $4^{\text {th }}$ Edition 1997 WHO, Geneva.

[10] Yang Li, Ye Zhang, Ran Yang, Qiong Zhang, Jing Zou and Deying Kang. Associations of social and behavioural factors with early childhood caries in Xiamen city in China. International Journal of Paediatric Dentistry 2010; 21:103-11

[11] Raadal M, Elkhinder EF, Rasmussen P. The prevalence of caries in group of children aged 4-5 and 7-8 years in Khartoum, Sudan. International Journal of Pediatric Dentistry1993; 3:9-15.

[12] Mousumi Goswami Singh,Seema Chaudhary,Naveen Manuja and Zohra Jabin. Association of feeding patterns and oral hygiene practices with early childhood caries in 3-6 year old children in Moradabad city. Journal of Indian Association of Public health Dentistry 2010; 15:121-25.

[13] Yashoda R, Anuradha KP, Baskar DJ, Hiremath S.S. Dental Caries prevalence and treatment needs among Davangere Preschool Children. Journal of the Indian Association of Public Health Dentistry 2011;17:193-201.

[14] Wyne A, Darwish S, Adenubi J, Batata S, Khan N. The prevalence and pattern of nursing caries in Saudi preschool children. International Journal of Paediatric Dentistry 2001; 11:361-66.

[15] S.C.L. Chan, J.S.J. Tsai, N.M. King. Feeding and oral hygiene habits of preschool children in Hong Kong and their caregiver's dental knowledge and attitudes. International Journal of Peadiatric Dentistry 2002; 12:322-31.

[16] Simin Z. Mohebbi, Jorma I. Virtanen, Mojtaba Vahid-Golpayegani, Miira M. Vehkalahti. Early childhood caries and dental plaque among 1-3year olds in Tehran, Iran. Journal of Indian Society of Pedodontics and Preventive Dentistry 2006:177-81.

[17] Chaiana Piovesan, Fausto M. Mendes, Fabiana V. Ferreira, Renata S. Guedes, Thiago M. Ardenghi. Socioeconomic inequalities in the distribution of dental caries in Brazilian preschool children. Journal of Public Health Dentistry 2010;70:319-26.

[18] Grytten J, Rosson I, Holst D, steele L. Longitudinal study of dental health behaviors and other caries predictors in early childhood. Community Dentistry and Oral Epidemiology 1988; 16:356-59.

[19] Chosack A, Cleaton JP, Matejka J, Fatti P. Social class, parents education and dental caries in 3 to 5 year old children. J DASA 1990;45:5-7.

[20] Grindefjord M, Datillof G, Ekstrom G, Hoje B, Modeer T. Caries prevalence in 2-5 year old children. Caries Research 1993; 27:505-10. 